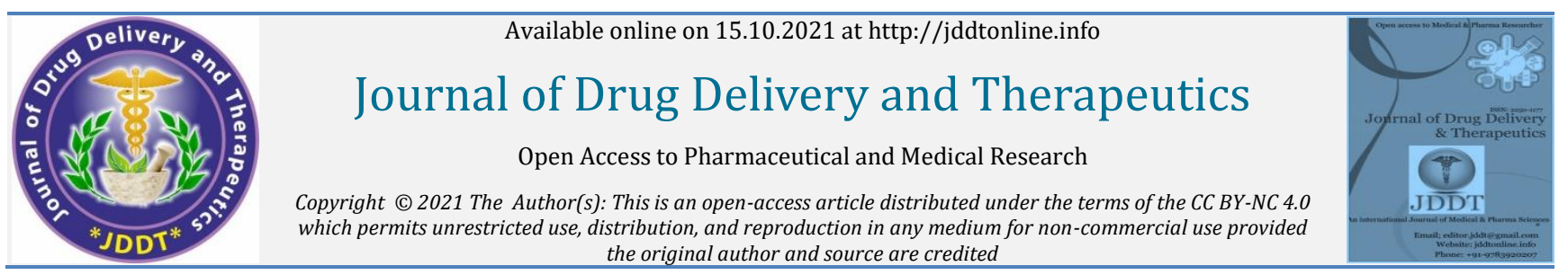

Open Access Full Text Article the original author and source are credited
and

\title{
Effect of Consuming Different Varieties of Bambara Groundnut (Vigna subterranea) Seeds on Glycaemia and Lipid Profile of Diabetic and Non- Diabetic Rats
}

\author{
Mhya Daniel Hassan* (D), Mohammed Abdulrashid (D) \\ Department of Medical Biochemistry, Faculty of Basic Medical Science, Abubakar Tafawa Balewa University, P.M.B. 0248, Bauchi, Nigeria
}

Article Info:

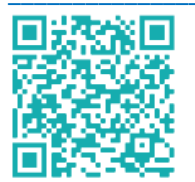

\section{Article History:}

Received 06 August 2021 Reviewed 14 September 2021 Accepted 19 September 2021 Published 15 October 2021

\section{Cite this article as: \\ Mhya DH, Mohammed A, Effect of Consuming Different Varieties of Bambara Groundnut (Vigna subterranea) Seeds on Glycaemia and Lipid Profile of Diabetic and Non-Diabetic Rats , Journal of Drug Delivery and Therapeutics. 2021; 11(5-S):6-12}

DOI: http://dx.doi.org/10.22270/jddt.v11i5-S.5011

\section{*Address for Correspondence:}

Mhya Daniel Hassan, Department of Medical Biochemistry, Faculty of Basic Medical Science, Abubakar Tafawa Balewa University, P.M.B. 0248, Bauchi, Nigeria

ORCID ID: https://orcid.org/0000-0002-4915-5981

\section{Abstract}

Background: Bambara groundnut seed is reported to possess high fibre and good nutritional content, and is locally used as a daily dietary therapy by diabetic patients in northern Nigeria. The plant seeds are of different varieties and whether the antidiabetic effect may vary with the varieties is largely unknown. This has prompted the current study to investigate effect of consuming different varieties of Bambara groundnut seeds on glycaemia and lipid profile of diabetic and non-diabetic rats.

Materials and Methods: Bambara groundnut seed's varieties were processed into flour and use in formulating feeds which were given to diabetic and non-diabetic rats as follows; group A (ALK01 feed), group B (ALK02 feed), group C (ALK03 feed), group D (ALK04 feed), group E (Basal feed), and group F (Normal animal's feed) for 28 days during which blood glucose and weights were measured weekly while lipid profile was assayed at the end of the study.

Results: The result of the study showed continuous increase in glycemic levels for diabetic rats fed basal and normal feeds compared to those fed plant seed formulated feeds. While, glycemic levels for non-diabetic rats fed plant seed formulated feeds, normal or basal feeds remain within normal range. The lipid components of diabetic rats fed basal and normal feeds were elevated and are significantly different $(P<.05)$ from those fed plant seed formulated feeds.

Conclusion: The study concluded that consumption of different varieties of Bambara groundnut seed could ameliorate hyperglycemia and hyperlipidemia by a variety dependent manner.

Keywords: Bambara groundnut, seed varieties, effect, glycaemia, lipid profile, rats

\subsection{INTRODUCTION}

Diabetes mellitus resulted by inability of the pancreas to produce insulin or respond of cells to insulin which is characterized by an elevation of glucose in the blood. The incidence of the disease in the many nations including African nations have been reported to be on the increase where changes in the type of diets consumed is considered as one of the major contributor ${ }^{1}$. The low prevalence of diabetes mellitus earlier observed in Africa was attributed to the rich biodiversity and high consumption of natural foods by Africans 2 .

Managing diabetes mellitus via healthy feeding (diet) is one of the important legs of the tripod for diabetes management $3,4,5$. Consumption of diet with low glycemic index (GI) but rich fibre has been recommended as one of the ways of achieving low plasma glucose excursion ${ }^{6}$. Several investigations have showed that, low GI foods, such as legumes, provide slower, more consistent source of glucose to the bloodstream, thereby stimulating less insulin release than high GI foods 7,8 . Legumes like beans or their products was found to have low $\mathrm{GI}^{9,10}$ and have been recommended as major component of daily dietary therapy for persons with diabetes ${ }^{11}$.

Bambara groundnut (Vigna subterranea L. Verdc or Voandzeia subterranea) is one of the legumes referred to as beans. It is an indigenous leguminous African crop that is grown across the continent ${ }^{12}$. It is commonly found in Nigeria and known locally as; "Okpa" (Igbo), "Epa-roro" (Yoruba) and "Kwaruru" or "Gurjiya" (Hausa). There are about seven varieties of Bambara groundnut seed which are mainly recognized by their seed-color or design. These include: black seed, red seed, cream/black eye seed, cream/brown eye seed, cream/no eye seed, speckled/flecked/spotted purple seed and brown (light or dark) seed ${ }^{13}$.

The plant is mainly grown for its seeds constitute complete foodstuff as it has been reported to contain protein, carbohydrate and lipid in reasonable quantities where is consumed at different stages of maturation ${ }^{14}$. The dried seeds are sometimes roasted and eaten as snacks or ground into flour 15. Study showed that consumption of fermented diet of Bambara groundnut seeds improved antioxidant 
regimen in experimentally induced diabetes ${ }^{1,16}$. In a recent study by the authors, consumption of feed formulated from the plant seeds was reported to be safe and has the potential to ameliorate diabetic hepatic and renal failure in rats ${ }^{17}$. A lot of traditional foods which found to have fewer/no side effects, low cost, ready available and possess both dietary and therapeutic functions have been encouraged to be developed as nutraceutics ${ }^{18}$.

Bambara groundnut seed may be one of the nutraceutics where its consumption led to amelioration of hyperglycemic ${ }^{16}$ and other related diabetic complications ${ }^{17}$. However, the plant seeds are found to be of several varieties and whether the glycemic lowering effect may vary with the varieties is largely unknown. This has prompted the current study to investigate effect of consuming different varieties of Bambara groundnut seeds on glycemic and lipid profile of diabetic and non-diabetic rats.

\subsection{MATERIALS AND METHODS}

\subsection{Materials}

In this study, the following materials were used; plastic cages consisting of feeding container and water bottle for rats, Oncall plus glucometer, weighing scale, spectrophotometry, centrifuge and oven.

\subsubsection{Experimental plant sample}

The different varieties of Bambara groundnut seeds were purchased directly from farmers in Alkaleri LGA of Bauchi State, North-East Nigeria. They were identified by a taxonomist at the Institute of Forestry, Jos, Plateau State. The four varieties were identified as ALK01 (cream/black eye seed), ALK02 (light brown seed), ALK03 (cream seed), and ALK04 (black seed). The seeds were dehulled then heated at $60^{\circ} \mathrm{C}$, cooled and grounded into flour using a mechanical grinder. The flour were kept at $25^{\circ} \mathrm{C}$ in an air tight bags until needed.

\subsubsection{Feed formulation}

The formulated feed containing flour of Bambara groundnut seed varieties composed of the following: Bambara groundnut seed flour (56\%), Cray-fish (20\%), vegetable oil $(5 \%)$, rice bran $(4 \%)$, sucrose $(10 \%)$, Vitamin/mineral mixture (5\%), respectively. The control feed used was animal feed (Grower's mash) which represented a wellbalanced diet consisting of significant percentage of carbohydrate, protein, fats (lipid), vitamins and minerals while the basal feed composed of same ingredients as the experimental feeds except that Bambara groundnut seed flour was replaced with corn-flour (56\%) as prepared by Olubunmi et al 19. The Bambara groundnut seed varieties formulated feeds were tag as; ALK01 feed, ALK02 feed, ALK03 feed and ALK04 feed.

\subsubsection{Experimental animal}

A total of sixty (60) male albino rats were used in the study. They were grouped into 12 groups of 5 rats each promptly labelled A, B, C, D, E and F. Group A-D are rats fed different variety of Bambara groundnut seed formulated feeds, group E rats fed basal feed while group $F$ rats fed normal feed (Animal feeds). The rats were acclimatized for two weeks before commencement of study. During this period they were fed normal animal feed and tap water before placing them on the varieties of Bambara groundnut seed formulated diets. Each rats' group was fed with a specific feed and tap water daily as follows:
Group A1: non-diabetic rats fed ALK01 feed

Group A2: diabetic rats fed ALK01 feed

Group B1: non-diabetic rats fed ALK02 feed

Group B2: diabetic rats fed ALK02 feed

Group C1: non-diabetic rats fed ALK03 feed

Group C2: diabetic rats fed ALK03 feed

Group D1: non-diabetic rats fed ALK04 feed

Group D2: diabetic rats fed ALK04 feed

Group E1: non-diabetic rats fed basal feed

Group E2: diabetic rats fed basal feed

Group F1: non-diabetic rats fed normal animal feed

Group F2: diabetic rats fed normal animal feed

\subsection{Feed and Water Intake Estimations}

During the experiment, feed and water intake were recorded daily from each group. Feed was weighed using a weighing scale to ascertain the quantity given and the remnants in each rat groups after 24 hours. The volume of water given and remain after 24 hours was measured using a graduated measuring cylinder $(1000 \mathrm{ml})$.

\subsection{Animal blood glucose determination}

Blood glucose of the experimental animals (Wistar albino rats) were measured weekly using On-call glucometer. Rats were fasted over a 12 hour period before a fasting blood glucose test was done. Blood samples were collected after a sharp prick through the straight vein supplying the tail with sterilized lancets. Cotton wool swabs in $70 \%$ ethanol was used to first sterilize the surface of the tail, before pricking and first blood run-off, glucometer was used in the determination of blood glucose level where results are collected from its output reader. The results obtained from the glucometer was collated, recorded and stored out in the group's inventory.

\subsection{Animal Body Weight Determination}

Weight of experimental rats were weighed weekly throughout the 28 days period. They were weighed using a weighing balance and the weight of each rat was recorded weekly. Initial body weight before administration of the formulated feeds was recorded this was however done to obtain their weight before subjected to the experimental feeds while the weight measured during feeding helped determine the experimental animal's weight change to the experimental diets.

\subsection{Lipid Profile Determination}

Serum triglyceride (TG) was determined by Fossati and Prenape 20 method. A $1000 \mu \mathrm{l}$ of TG reagent was pipetted into a clean separate test tubes labelled as sample test, standard test and blank test. Then, $10 \mu \mathrm{l}$ of serum, standard and distilled water were added to the content in the tubes in an orderly manner, mixed and then incubated at $37{ }^{\circ} \mathrm{C}$ for 5 minutes. Then, the absorbance of the test and standard were read against the blank at $546 \mathrm{~nm}$.

Triglycerides conc $(\mathrm{mmol} / \mathrm{L})=$ Abs. of sample $/$ standard $^{*}$ $(200 \mathrm{mg} / \mathrm{dL})^{*}(0.0113 \mathrm{mmol} / \mathrm{L})$

Total Cholesterol (TC) was determined by Roeschlau et al 21 method. A $1000 \mu \mathrm{l}$ of Chloresterol reagent was pipetted into clean separate test tubes labelled as sample test, standard test and blank test. Then, $10 \mu \mathrm{l}$ of serum, standard and distilled water were added to the content in the tubes in an 
orderly manner, mixed and then incubated at $37{ }^{\circ} \mathrm{C}$ for 5 minutes. Then, the absorbance of the test and standard were read against the blank at $505 \mathrm{~nm}$.

Cholesterol conc. $(\mathrm{mmol} / \mathrm{L})=$ Abs. of sample $/$ standard $*$ $(200 \mathrm{mg} / \mathrm{dL}) *(0.0256 \mathrm{mmol} /)$.

High Density Lipoprotein Cholesterol (HDL-C) was determined by Lopes-Virella et al22 method. A $30 \mu \mathrm{l}$ of serum was mixed with $900 \mu \mathrm{l}$ of HDL-reagent and allowed to stand for $10 \mathrm{~min}$ at $25^{\circ} \mathrm{C}$ then was read at $550 \mathrm{~nm}$ as absorbance 1 . A $100 \mu \mathrm{l}$ HDL-reagent 2 was added to content in all tubes and kept at $250 \mathrm{c}$ for 5 minutes then absorbance 2 was read at $550 \mathrm{~nm}$.

HDL Cholesterol conc. $(\mathrm{mmol} / \mathrm{L})=$ Abs of sample $/$ standard x $34.8 \mathrm{mg} / \mathrm{dL} \times 0.0259 \mathrm{mmol} / \mathrm{L}$

LDL Cholesterol (LDL-C) and VLDL Cholesterol (VLDL-C) were estimated using Friedewald et al ${ }^{23}$ formula:

LDL - Cholesterol conc. $(\mathrm{mg} / \mathrm{dL})=[\mathrm{TC}-(\mathrm{HDL}-\mathrm{C}+$ Triglycerides /5)] and

VLDL-Cholesterol conc. $(\mathrm{mg} / \mathrm{dL})=[$ Triglycerides $/ 5]$.

\subsection{Determination of Serum Insulin Levels}

Serum insulin level was measured by an enzyme-linked immunosorbent assay (ELISA) method as described by Clark and Hales ${ }^{24}$. A $50 \mu \mathrm{l}$ of insulin calibrators, control and samples were pipetted into separate wells then $100 \mu \mathrm{l}$ of the insulin enzyme reagent was added to each well. The microplate was swirl gently for 30 seconds and incubated for 120 minutes at $25{ }^{\circ} \mathrm{C}$ after which the content of the micro-plate was discarded. Then, $350 \mu \mathrm{l}$ wash buffer was added and decanted trice followed by the addition of $100 \mu \mathrm{l}$ of the working substrate solution to all wells and incubated for 15 minutes. Finally, a $50 \mu \mathrm{l}$ of a stop solution was added and mixed gently for 20 seconds. Then, absorbance of content in each well was read at $450 \mathrm{~nm}$ using a micro-plate reader. The concentrations of insulin (ng/L) was ascertained from dose response curve of standard insulin.

\subsection{STATISTICAL ANALYSIS}

Data from the experiments were expressed as mean \pm standard deviation (SD). Means was analyzed by one way analysis of variance (ANOVA) and then compared by Duncan's multiple range test (DMRT) ${ }^{25}$. Significant difference was accepted at $P<0.05$. The statistical analysis was conducted using the computer software, statistical package for the social sciences (IBM SPSS version 21).

\subsection{RESULTS}

\subsection{Feed and Water Intake of Rats Fed Bambara groundnut Seed Formulated Feeds}

The mean weekly feed and water intake per rats' groups is presented in Table 1 . The study recorded low intake of the formulated feeds by the diabetic rats compare to those that were non-diabetic, whereas those that fed normal and basal feeds; the diabetic rats consumed more than the non-diabetic rats. The result for water intake showed high intake by the diabetic rats' groups in comparison to the non-diabetic rats throughout the experimental period. The feed formulated with ALK03 Bambara groundnut seed variety was the highest consumed by both diabetic and the non-diabetic rats.

\subsection{Blood Glucose Levels of Rats Fed Bambara Groundnut Seed Formulated Feeds}

Effect of feeding diabetic and non-diabetic rats with feed formulated with flour from Bambara groundnut seeds varieties are presented in Figure 1 . There were a gradually increase in glycemic levels of all diabetic rats' groups at the initiation of the experiment which later declined toward normal expect those that were fed basal and normal feeds. While, the changes in fasting blood glucose levels of non-diabetic rats fed Bambara groundnut seeds varieties formulated feed and those fed basal feed are still within normal range as compare with the rat's group fed normal animal feed. The highest reduction in fasting blood glucose was seen in diabetic rats fed ALK03 and ALK04 Bambara groundnut seed varieties formulated feeds by $\geq 45 \%$ and least with diabetic rats fed ALK01 Bambara groundnut seed variety by $23 \%$.

\subsection{Change in Insulin Levels of Rats Fed Bambara Groundnut Seeds Formulated Feeds}

Figure II shows the effect of feeding different varieties of Bambara groundnut seed formulated feeds on insulin level of diabetic and non-diabetic rats. The study recorded a decrease in serum insulin from diabetic rats groups fed basal and normal feeds in comparison to those fed different varieties of the plant seed formulated feeds.

\subsection{Change in Body Weight of Rats Fed Bambara Groundnut Seed Formulated Feeds}

Figure III shows the effect of feeding Bambara groundnut seeds varieties formulated feeds on body weight of diabetic and non-diabetic rats. The study recorded an initial loss in body weights of both diabetic and non-diabetic rats groups which were later improved by the non-diabetic rats and continued to increase throughout the experiment. The loss in body weight of diabetic rats fed Bambara groundnut seed varieties formulated feeds were retarded as the study advances compare to rat's fed basal feed. Diabetic rats fed ALK04 Bambara groundnut seed variety formulated feed had the highest retardation of body weight loss while those that fed ALK03 Bambara groundnut seed variety formulated feed showed low retardation of weight loss.

\subsection{Impact of Feeding Bambara Groundnut Seed Formulated Feeds on Lipid Profile of Rats}

Effect of feeding Bambara groundnut seeds varieties formulated feeds on lipid profile in diabetic and non-diabetic rats are presented in Table 2. There were significant difference $(p<0.05)$ in lipid profile alterations between diabetic and non-diabetic rats fed Bambara groundnut seeds varieties formulated feeds. When compare with the diabetic rats fed basal and normal feeds, the study observed a significant elevation in lipid profile of those rats fed basal and normal feeds compare to those fed Bambara groundnut seeds varieties formulated feeds. In non-diabetic rats' groups, there were also changes in lipid profile but are still within normal range as compare with the rat's group fed normal feed. A highest reduction in lipid profile like triglyceride was recorded from diabetic rats fed ALK03 Bambara groundnut seed variety formulated feed whereas high reduction in total cholesterol was recorded in those rats fed ALK01 Bambara groundnut seed variety formulated feed.

\subsection{DISCUSSION}

Bambara groundnut seed is reported to possess high fiber and good nutritional content where its consumption was reported to ameliorate diabetes and its related complications ${ }^{16,17}$. It is locally used as one of the daily dietary therapy for persons with diabetes in northern part of Nigeria. But, the plant seeds are of different varieties and whether the glycemic lowering effect may vary with the Feeds varieties is largely unknown. 
Table 1: Feed and Water Intake of Diabetic and Non-diabetic Rats Fed Different Varieties of Bambara Groundnut Seed Formulated

\begin{tabular}{|c|c|c|c|c|c|c|c|c|c|c|c|c|}
\hline \multicolumn{13}{|c|}{ Animal Grouping $(n=5)$} \\
\hline & $\begin{array}{l}\text { Group } \\
A_{1}\end{array}$ & $\begin{array}{l}\text { Group } \\
\mathrm{A}_{2}\end{array}$ & $\begin{array}{l}\text { Group } \\
\mathrm{B}_{1}\end{array}$ & $\begin{array}{l}\text { Group } \\
\mathrm{B}_{2}\end{array}$ & $\begin{array}{l}\text { Group } \\
\mathrm{C}_{1}\end{array}$ & $\begin{array}{l}\text { Group } \\
\mathrm{C}_{2}\end{array}$ & $\begin{array}{l}\text { Group } \\
D_{1}\end{array}$ & $\begin{array}{l}\text { Group } \\
\mathrm{D}_{2}\end{array}$ & $\begin{array}{l}\text { Group } \\
\mathrm{E}_{1}\end{array}$ & $\begin{array}{l}\text { Group } \\
\mathrm{E}_{2}\end{array}$ & $\begin{array}{l}\text { Group } \\
\mathrm{F}_{1}\end{array}$ & $\begin{array}{l}\text { Group } \\
\mathrm{F}_{2}\end{array}$ \\
\hline \multirow{3}{*}{$\begin{array}{l}\text { Water } \\
\text { Intake } \\
\text { (ml/wee } \\
\text { k/ } 5 \text { rats) }\end{array}$} & 129.50 & 204.37 & 153.54 & 236.79 & 191.14 & 247.43 & 172.50 & 252.67 & 136.64 & 267.99 & 94.86 & 261.8 \\
\hline & \pm & \pm & \pm & \pm & \pm & \pm & \pm & \pm & \pm & \pm & \pm & $2 \pm$ \\
\hline & $21.23^{\mathrm{b}}$ & $29.00^{\mathrm{d}}$ & $18.21^{c}$ & $39.12^{\mathrm{e}}$ & $18.76^{c}$ & $63.43 \mathrm{e}$ & $22.31^{\mathrm{c}}$ & $57.95^{\mathrm{e}}$ & $13.30^{\mathrm{b}}$ & $66.65^{f}$ & $16.85^{a}$ & $50.18^{\mathrm{f}}$ \\
\hline Feed & 129.39 & 106.90 & 112.78 & 105.62 & 129.95 & 131.71 & 60.61 & 43.32 & 56.12 & 60.88 & 53.04 & 87.96 \\
\hline Intake & \pm & \pm & \pm & \pm & \pm & \pm & \pm & \pm & \pm & \pm & \pm & \pm \\
\hline $\begin{array}{l}\text { (g/week/ } \\
5 \text { rats) }\end{array}$ & $26.81^{\mathrm{e}}$ & $15.94^{d}$ & $22.43^{\mathrm{d}}$ & $22.60^{\mathrm{d}}$ & $27.53^{e}$ & $26.14^{\mathrm{e}}$ & $8.09^{b}$ & $15.68^{a}$ & $3.60^{a}$ & $6.87^{b}$ & $7.58^{a}$ & $13.26^{c}$ \\
\hline
\end{tabular}

Values are Mean \pm SD of 7 determinations. Values with different superscript letter across the rows are significantly different at $\mathrm{P}<.05$

Group A1: non-diabetic rats fed ALK01 feed

Group B1: non-diabetic rats fed ALK02 feed

Group C1: non-diabetic rats fed ALK03 feed

Group D1: non-diabetic rats fed ALK04 feed

Group E1: non-diabetic rats fed basal feed

Group F1: non-diabetic rats fed normal feed
Group A2: diabetic rats fed ALK01 feed

Group B2: diabetic rats fed ALK02 feed

Group C2: diabetic rats fed ALK03 feed

Group D2: diabetic rats fed ALK04 feed

Group E2: diabetic rats fed basal feed

Group F2: diabetic rats fed normal feed

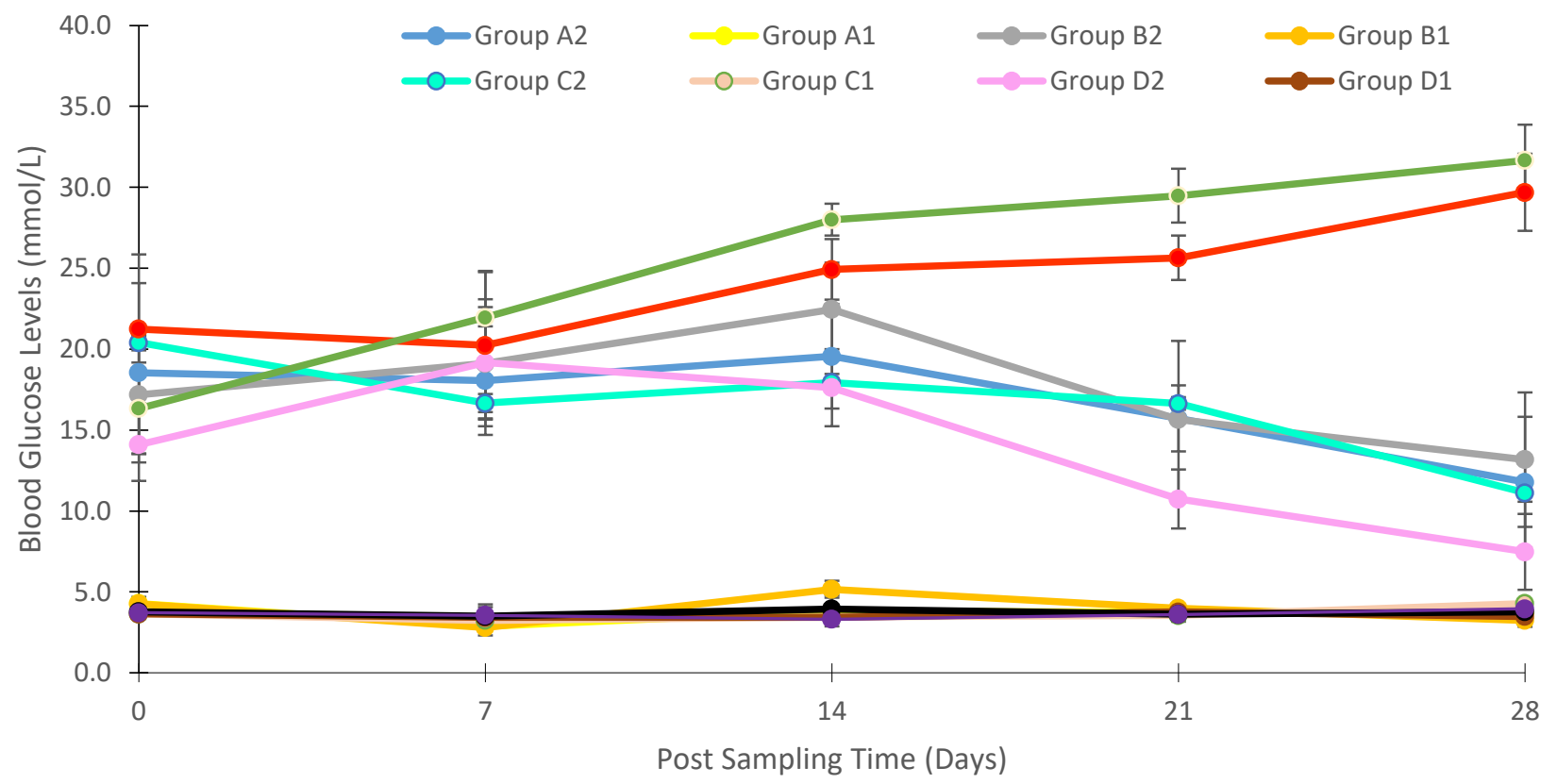

Figure I: Effect of Consuming Different Varieties of Bambara Groundnut Seed Formulated Feeds on Blood Glucose of Nondiabetic and Diabetic Rats

Group A1: non-diabetic rats fed ALK01 feed Group B1: non-diabetic rats fed ALK02 feed Group C1: non-diabetic rats fed ALK03 feed Group D1: non-diabetic rats fed ALK04 feed Group E1: non-diabetic rats fed basal feed Group F1: non-diabetic rats fed normal feed
Group A2: diabetic rats fed ALK01 feed

Group B2: diabetic rats fed ALK02 feed

Group C2: diabetic rats fed ALK03 feed

Group D2: diabetic rats fed ALK04 feed

Group E2: diabetic rats fed basal feed

Group F2: diabetic rats fed normal feed 


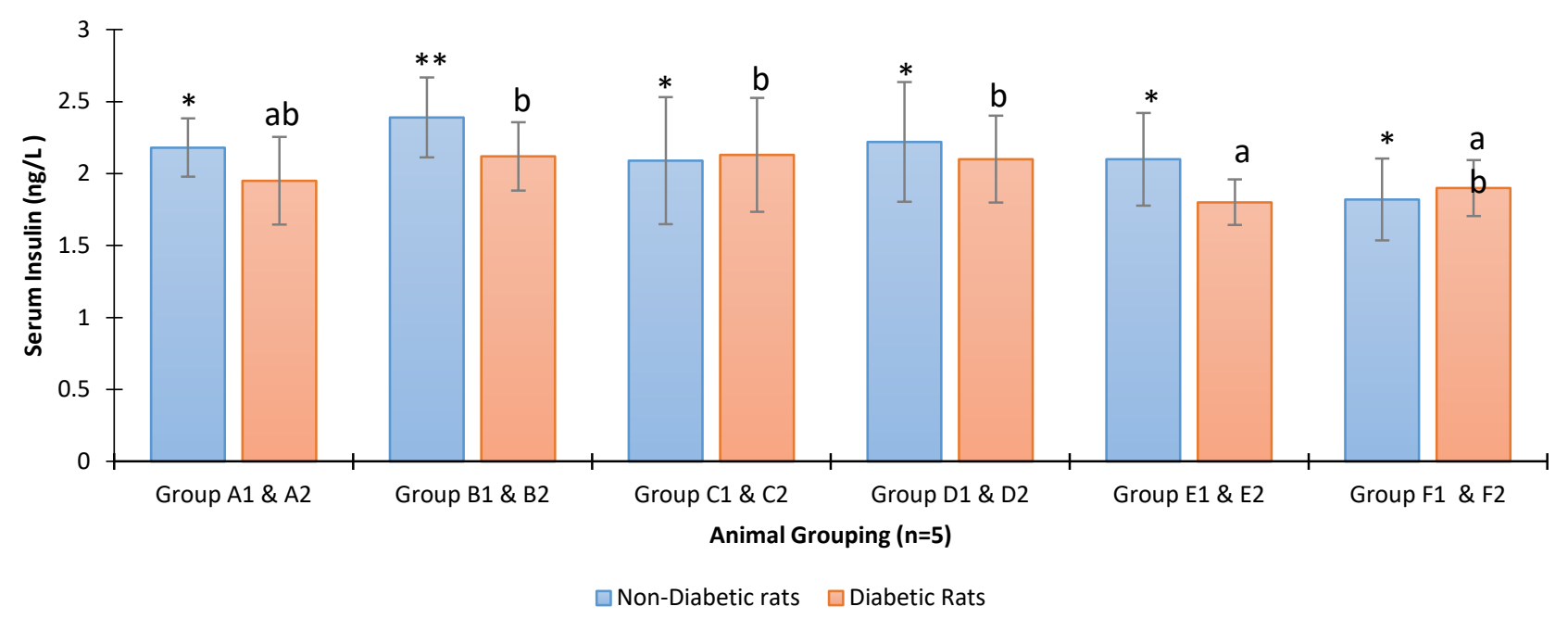

Figure II: Effect of Consuming Different Varieties of Bambara Groundnut Seed Formulated Feeds on Insulin Level of Diabetic and Non-diabetic Rats

Bars with different superscript are significantly different at $\mathrm{P}<0.05$

Group A1: non-diabetic rats fed ALK01 feed Group A2: diabetic rats fed ALK01 feed

Group B1: non-diabetic rats fed ALK02 feed

Group B2: diabetic rats fed ALK02 feed

Group C1: non-diabetic rats fed ALK03 feed

Group C2: diabetic rats fed ALK03 feed

Group D1: non-diabetic rats fed ALK04 feed

Group D2: diabetic rats fed ALK04 feed

Group E1: non-diabetic rats fed basal feed

Group E2: diabetic rats fed basal feed

Group F1: non-diabetic rats fed normal feed

Group F2: diabetic rats fed normal feed

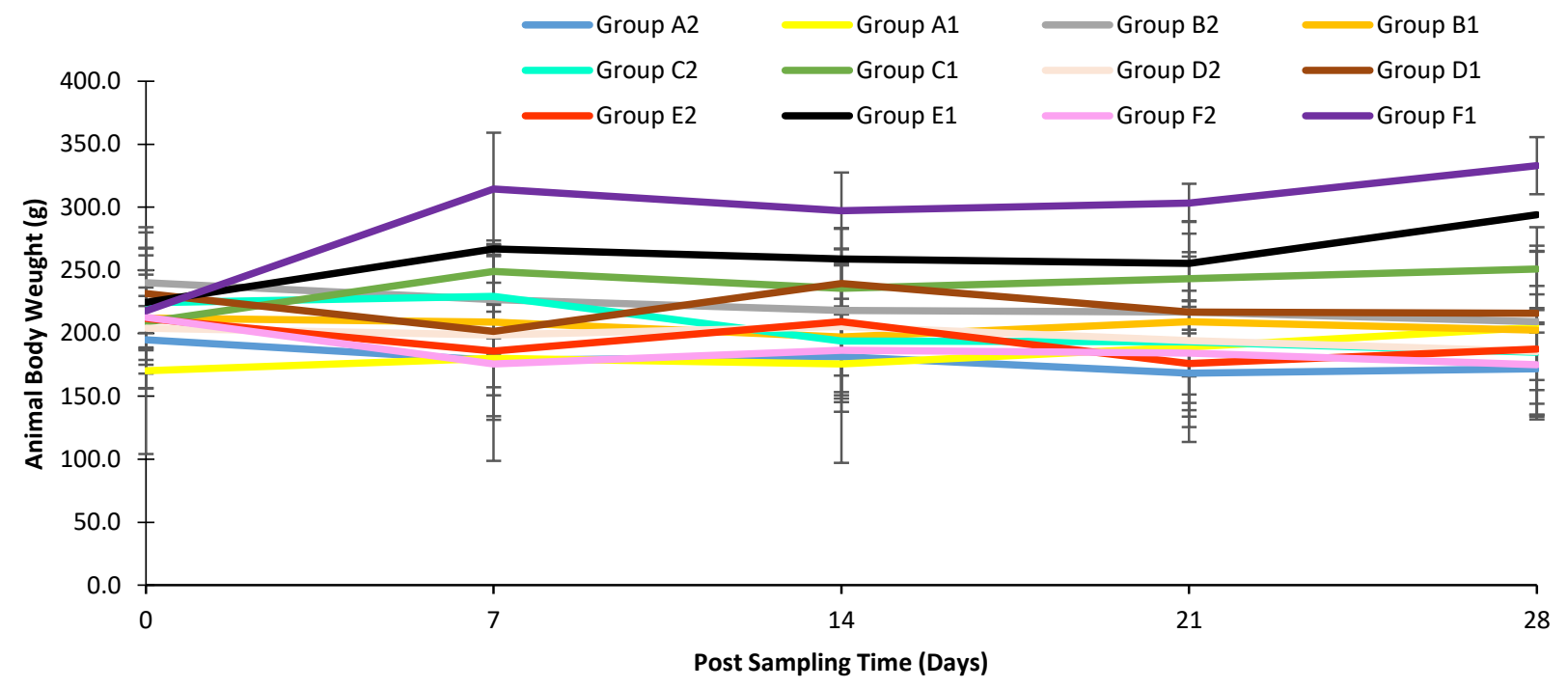

Figure III. Change in Body Weight of Non-diabetic and Diabetic Rats Following Feeding with Different Varieties of Bambara Groundnut Seed Formulated Feeds

Group A1: non-diabetic rats fed ALK01 feed

Group B1: non-diabetic rats fed ALK02 feed

Group C1: non-diabetic rats fed ALK03 feed

Group D1: non-diabetic rats fed ALK04 feed

Group E1: non-diabetic rats fed basal feed

Group F1: non-diabetic rats fed normal feed
Group A2: diabetic rats fed ALK01 feed

Group B2: diabetic rats fed ALK02 feed

Group C2: diabetic rats fed ALK03 feed

Group D2: diabetic rats fed ALK04 feed

Group E2: diabetic rats fed basal feed

Group F2: diabetic rats fed normal feed 
Table 2: Effect of Consuming Different Varieties of Bambara Groundnut Seed Formulated Feeds on Lipid Profile of Diabetic and

Non-diabetic Rats

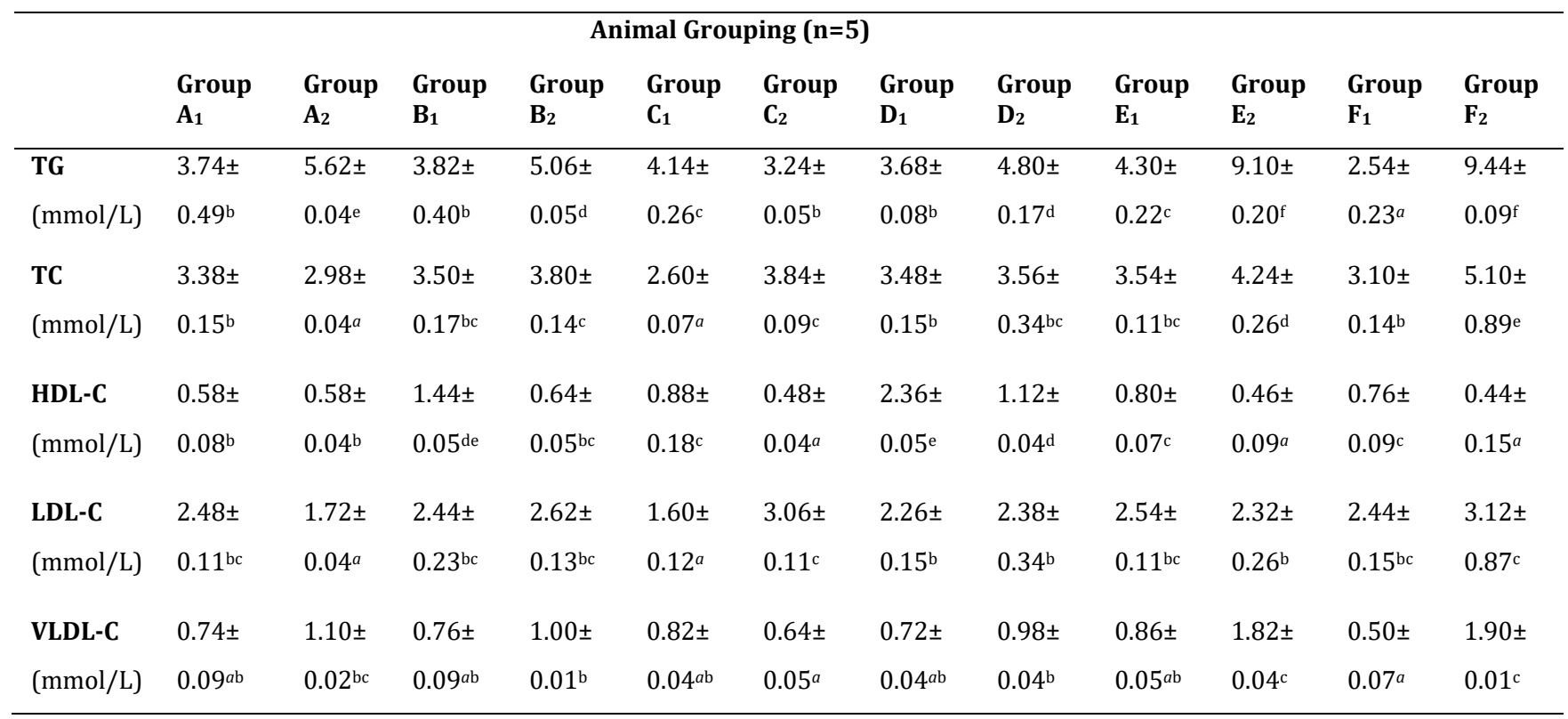

Values are Mean \pm SD of 5 determinations. Values with different superscript letter across the rows are significantly different at P<.05

Group A1: non-diabetic rats fed ALK01 feed Group B1: non-diabetic rats fed ALK02 feed Group C1: non-diabetic rats fed ALK03 feed Group D1: non-diabetic rats fed ALK04 feed Group E1: non-diabetic rats fed basal feed Group F1: non-diabetic rats fed normal feed
Group A2: diabetic rats fed ALK01 feed

Group B2: diabetic rats fed ALK02 feed

Group C2: diabetic rats fed ALK03 feed

Group D2: diabetic rats fed ALK04 feed

Group E2: diabetic rats fed basal feed

Group F2: diabetic rats fed normal feed
This has prompted the current study to investigate effect of consuming different varieties of Bambara groundnut seeds on glycemic and lipid profile of diabetic and non-diabetic rats. Where the results of the study showed consumption of Bambara groundnut seed led to the amelioration of hyperglycemia and hyperlipidemia in diabetic rats. The antidiabetic efficacy of the plant seeds seem to vary with varieties where ALK 04 emerge the most effective.

The reduction in fasting blood glucose in diabetic rats fed different varieties of Bambara groundnut seeds formulated feeds may be attributable to their high fibre and some phytochemicals present, attesting to the fact that Bambara groundnut seeds plays a major role in antidiabetic activity ${ }^{16}$. The difference observed in the glycemic lowering effect by the different varieties of the plant seeds may be attributable to the difference in their glycemic index and load as determined by the authors' previous study ${ }^{26}$ hence variation in their antidiabetic efficacy. Declined in consumption of Bambara groundnut seeds formulated feeds by the diabetic rats compared to non-diabetic rats could be due to some physiological changes induced by the diabetes condition.

Diabetic condition is associated with loss in body weight. In this study, the loss of body weight by the diabetic rats may resulted from relative or absolute deficiency of insulin due to defective $\beta$ - cells caused by STZ injection which is accompanied by an increased breakdown of muscle proteins ${ }^{27}$. Consumption of Bambara groundnut seeds formulated feeds might have minimized the degradation of muscle proteins at the expense of facilitating cellular utilization of glucose hence preventing body weight loss.

Impaired carbohydrate utilization in diabetes mellitus was reported to have promoted lipolysis, which leads to dyslipidemia according to Nesto 28 , and this is characterized by hypertriglyceridemia and low HDL-cholesterol level among others 29. Different alterations in serum lipid components like triglyceride, total cholesterol, LDLcholesterol, VLDL-cholesterol, and HDL-cholesterol observed in diabetic rats fed basal and normal feeds agreed with the above findings while declined in these parameters from diabetic rats fed Bambara groundnut seeds formulated feeds is an indication that the plant seeds contains components with antihyerlipidemic properties hence, may play a significant role in combating diabetic complications. According to some earlier study, Bambara groundnut seed was reported to possess hypo-lipidemic activity where it was suggested to be used in addressing the increase prevalence of diabetes complications ${ }^{1}$. The reduction in lipid components by Bambara groundnut seeds have been attributed to a phytochemical which was identified as vicilin, a globulin storage protein ${ }^{30}$. However, this present study have not identify any phytochemical likely to be responsible for the antihyperlipidemic effect, findings from the authors previous study could suggest that the phytochemicals screened might have play a part in exerting the antihyperlipidemic activities observed ${ }^{26}$.

\section{CONCLUSION}

The study concluded that consumption of different varieties of Bambara groundnut seed could led to the amelioration of hyperglycemia and hyperlipidemia by a variety dependent manner. Where an ALK 04 seed variety emerge as the most effective and is recommended for further investigation and procession as dietary supplement for managing diabetes and other related ailments.

Ethical Approval: All authors hereby declare that "Principles of laboratory animal care" (NIH publication No. 8523, revised 1985) were followed, as well as specific national laws where applicable. All experiments have been 
examined and approved by the appropriate ethics committee."

Competing Interests: Authors have declared that no competing interests exist.

Author's Contribution: D.H. Mhya and A. Mohammed designed and performed the experiments and collected data. D.H.Mhya analysis the data, discussed the results and wrote the first draft of the manuscript. A. Mohammed supervised, directed and managed the finance for the study. Both authors proofread and finally approved the version to be published.

Acknowledgements: Authors wish to thank the Tertiary Education Trust Fund (TETFUND), Nigeria for funding support, the Vice Chancellor (Prof. Muhammad Ahmad Abdulazeez) and the entire management staff of the Abubakar Tafawa Balewa University (ATBU), Bauchi, Nigeria for approval and providing avenue to conduct the study.

\section{REFERENCES}

1. Nwajiobi OJ, Ogbunugafor HA, Ezenwelu CO, Oche B, Nwokeke CC and Ogoke JT. The effect of a combination of D. dumetorum and V. subterranea feed on blood glucose level and serum lipid profile in alloxan-induced diabetic rats. Inter J Agri Biosci, 2016; 5:109-112.

2. Udenta EA, Obizoba IC, Oguntibeju 00. Antidiabetic effects of Nigerian indigenous plant foods/diets. Antioxidant -Antidiabetic Agents and Human Health. 2014; 3. doi.10.5772/ 57240.

3. Mann JI. Diet and diabetes. Diabetologia, 1980; 18:89-95. doi.10.1007/BF00290 48311. https://doi.org/10.1007/BF00290483

4. Little D. Non-pharmacological management of diabetes: The role of diet and exercise. Geriatrics Aging. 2003; 6:27-9.

5. Michael JF. Diabetes treatment, part 1: Diet and exercise. Clin. Diabetes., 2007; 25:105-9. https://doi.org/10.2337/diaclin.25.3.105

6. Wolever TMS, Katzman-Relle L, Jenkins AL, et al. Glycaemic index of 102 complex carbohydrate foods in patients with diabetes. Nutr. Res. 1994; 14:651-69. doi.10.1016/S02715317(05)802015 https://doi.org/10.1016/S0271-5317(05)80201-5

7. Jenkins DJ, Wolever TM, Taylor RH. Glycaemic index of foods: a physiological basis for carbohydrate exchange. Am J Clin. Nutr., 1981,34:362-6. https://doi.org/10.1093/ajcn/34.3.362

8. Thomas D, Elliott EJ, Baur. Low glycaemic index or low glycaemic load diets for overweight and obesity. Cochrane Database Syst. Rev., 2007; 3:CD005105. https://doi.org/10.1002/14651858.CD005105.pub2

9. Ohwovoriole AE and Johnson TO. Which Nigerian food for the diabetic? Nig. J. Nutr. Sci., 1984; 5:59-62.

10. Oboh H, Osagie A, Omotosho A. Glycaemic response of some boiled legumes commonly eaten in Nigeria. Diabetol. Croatica., 2010; 39:125-131.

11. Olarinoye JK, Ano- Edwards GH, Alade I. Knowledge and practice of medical nutrition therapy by diabetes care givers in Ilorin, Nigeria. Nig. Med. Pract., 2007; 51:55-8. https://doi.org/10.4314/nmp.v51i4.28842

12. Olanipekun BF, Otunola ET, Adejuyitan JA, Adeyanju . Proximate and fatty composition of bambara groundnut (Voandzeia subterranea) as Influenced by fermentation with a combination of Rhizopus oligosporous and R. nigricans. Transnat J Sci Technol., 2012; 2:107-110.

13. Bambara groundnuts (Vigna subterranean): Production guideline for Bambara groundnuts. Directorate agricultural information services, department of agriculture, forestry and fisheries, Republic of South Afric. 2011; 110. Available: https://www.nda.agric.za/docs/Brochures/P rodguideBambara.pdf
14. National Research Council (NRC, 2006). Lost crops of Africa: Volume II: Vegetables. http://www.nap.edu/ catalog/11763.html.

15. Oyenuga V.A. Nigerian Foods and Feeding-Stuffs. Their Chemistry and Nutritive Value,. Ibadan University Press, 1968, Ibadan.

16. Adedayo OA and Ganiyu O. Attenuation of oxidative stress and hepatic damage by some fermented tropical legume condiments diets in streptozotocin-induced diabetes in rats. Asian Pacific J Trop Med., 2012; 5:692-697. https://doi.org/10.1016/S19957645(12)60108-4

17. Mohammed A and Mhya DH. Effects of Consuming Different Varieties of Bambara Nut (Vigna subterranea) Seeds on Liver and Kidney of Diabetic and Non-diabetic Subject. Journal of Advances in Biology \& Biotechnology, 2021; 24:25-35. doi: 10.9734/JABB/2021/v24i630219. https://doi.org/10.9734/jabb/2021/v24i630219

18. Neelesh M, Sanjay J, and Sapna M,. Antidiabetic Potential of Medicinal Plants. Acta Poloniae Pharmaceutica-Drug Res, 2010; 67: $113-118$

19. Olubunmi A, Oluwatosin A, Dare A. Antioxidative potentials of cooked bambara groundnut based diet (Vigna subterranean) on lipid peroxidation status in pretreated alloxan induced diabetic rats. World Journal of Pharmacy and Pharmaceutical Sciences., 2017; 6:62-76. https://doi.org/10.20959/wjpps20174-8891

20. Fossati $P$ and Prencipe L. Serum triglycerides determined colorimetrically with an enzyme that produces hydrogen peroxide. Clin. Chem., 1982; 28:2077-2080. https://doi.org/10.1093/clinchem/28.10.2077

21. Roeschlau P, Bernt E, Gruber W. Enzymatic determination of total cholesterol in serum. Z. Klin. Chem. Klin. Biochem., 1974; 12:226-226.

22. Lopes-Virella MF, Stone P, Ellis S, Colwell JA. Cholesterol determination in highdensity lipoproteins separated by three different methods. Clin. Chem., 1977; 23:882-884. https://doi.org/10.1093/clinchem/23.5.882

23. Friedewald WT, Levy RI, Fredrickson DS. Estimation of the concentration of low density lipoprotein cholesterol in plasma, without use of the preparative ultracentrifug. Clin. Chem., 1972; 18:499502. https://doi.org/10.1093/clinchem/18.6.499

24. Clark P.M.S. and Hales C.N. How to measure plasma insulin. Diabetes/Metab. Rev., 1994; 10(1):79-90. https://doi.org/10.1002/dmr.5610100203

25. Duncan BD. Multiple range test for correlated and heteroscedastic means. Biometrics., 1957; 13:359-364 https://doi.org/10.2307/2527799

26. Mohammed A and Mhya DH. Evaluation of phytochemical constituents, proximate contents and glycemic index of bambara groundnut (Vigna subterranea L. Verdc) varieties grown in Northeastern Nigeria. Afri J Biochemistry Res., 2021; 15:22-27. DOI: $10.5897 / A J B R 2021.1120$

27. Bastaki S. Diabetes mellitus and its treatment. Int. J. Diabetes Metab., 2005; 13: 111-134 https://doi.org/10.1159/000497580

28. Nesto RW. Beyond low-density lipoprotein: addressing the atherogenic lipid triad in type 2 diabetes mellitus and the metabolic syndrome. Am J Cardiovasc Care, 2005; 5:379-387. https://doi.org/10.2165/00129784-200505060-00005

29. Granner DK. Hormones of the pancreas and gastrointestinal tract. In: Murray RK, DK Granner, PA Mayes, VW Rodwel (eds), 1996. Harper's Biochemistry, ed 24, Connecticut, USA, Appleton and Lange, 586-587

30. Okpuzor J, Ogbunugafor HA, Okafor U and Sofidiya MO Identification of protein types in Bambara groundnut seeds: perspectives for dietary protein supply in developing countries. EXCLI J, 2010; 9:17-28. 